(RESEARCH ARTICLE)

\title{
Morris water maze test on neuroprotective effects of ethanolic extract of oyster mushroom (Pleurotus ostreatus) against neurotoxicity of mercury chloride in albino rats (Rattus norvegicus)
}

\author{
Zitte Leelee Famii * and Bernard Seleke-Ere Favour \\ Department of Animal and Environmental Biology, University of Port Harcourt Nigeria.
}

Publication history: Received on 20 May 2019; revised on 28 August 2019; accepted on 29 August 2019

Article DOI: https://doi.org/10.30574/wjarr.2019.3.1.0035

\begin{abstract}
The neuroprotective effects of ethanolic extract of Pleurotus ostreatus against neurotoxicity of mercury on albino rats was studied using the spatial memory test (morris water maze test), this was conducted in order to know the extent of spatial memory impairments caused by mercury toxicity, and also to ascertain the neuroprotective effects of the mushroom against this toxicity. The study was conducted to determine the ability of the animal groups to identify and easily trace the location of an escape platform with the help of a spatial cues. Twenty four rats were distributed into six groups of four animals each. Group 1 (control), group 2 (250 mg/kg mushroom alone), group 3 (250 mg mushroom and $50 \mu \mathrm{g} / \mathrm{kg}$ mercury), group 4 (250 mg mushroom and $100 \mu \mathrm{g} / \mathrm{kg}$ mercury), group 5 (50 $\mu \mathrm{g} / \mathrm{kg}$ mercury alone) and group $6(100 \mu \mathrm{g} / \mathrm{kg}$ mercury alone). These animal groups were administered their respective treatments for a period of one month. Thereafter, the anti-depression and spatial memory test (Morris water maze) was carried out. The result indicated that, groups $1,2,3,4,5$ and 6 had mean values of $41.73 \pm 12.24,14.88 \pm 11.12,22.76 \pm 17.34$, $26.29 \pm 13.14,47.88 \pm 14.11$, and $80.26 \pm 82.15$ seconds respectively. These showed that mercury can be implicated as neuro-toxicant having caused high degree of depression with poor response abilities in the animals with mercury doses alone (groups 5 and 6) as against those administered mercury and mushrooms (groups 3 and 4). It was also seen that group 2 which was given mushroom alone had the best response, even better than the control. This concludes that $P$. ostreatus improves neuro function in animals against neurotoxicity of mercury.
\end{abstract}

Keywords: Mercury; Pleurotus ostreatus; Neuroprotection; Morris test; Neurotoxicity

\section{Introduction}

Heavy metal pollution has increased considerably at the global scale as a result of high industrial activities. Mercury $(\mathrm{Hg})$ contamination of the environment has received considerable attention because of its inherent toxicity to human $[1,2]$ Exposure to mercury may occur primarily by ingestion, inhalation and through the food chain.

Mercury compounds, including organic and inorganic forms, exhibit a variety of toxic effects, including neurotoxicity, hepatotoxicity, nephrotoxicity and gastrointestinal toxicity with ulceration and hemorrhage .Mercury produces strong inhibition of a large number of enzymes that have functional sulfhydryl (SH) groups [3].

Mercury exerts its influence by combining with the SH group of the enzyme leading to conformational changes and consequent inactivation. Past studies [4-7] have already documented the deleterious effects of heavy metal toxins in humans which may induce oxidative stress, lipid peroxidation, and inhibition of cognitive memory expression.

\footnotetext{
${ }^{*}$ Corresponding author

E-mail address: Leelee.zitte@uniport.edu.ng
} 
Mercury exposure has the potential to damage brain functioning, yet, remains not understood, its ability to react with and deplete sulfhydryl groups as well as to disrupt cell cycle progression and/or induce apoptosis in several tissues is well recognized, [6].

Moreover, mercury induced neurotoxicity is known to be mediated by reactive oxygen species (ROS) in different models by altering $\mathrm{Na}+\mathrm{K}+-\mathrm{ATPase}$ activity and mitochondrial function [8].

Recently, attention has been focused on the protective function of dietary antioxidants against harmful effects associated with heavy metal exposure. Some studies have focused their efforts on the protective effects of plants or natural compounds on various neuropathological conditions. Particularly important is the fact that it has been observed that plants/natural compounds are able to counteract metal-induced neurotoxicity under in-vivo conditions [9-10].

Mushrooms have been attracting attention of mankind since ancient times, and the use of mushroom as food is as old as human civilization. It has considerable importance in the human diet as it is rich in protein, nonstarchy carbohydrates, dietary fiber, minerals, and vitamin-B; and has no cholesterol, and negligible amount of fat. Mushroom proteins are of high quality and it contains an abundance of essential amino acids [11].

Pleurotus ostreatus is commonly known as 'oyster mushroom'. It is grown commercially around the world for food. $P$. ostreatus is used for mycoremediation purposes; the mycelia help the mushroom to obtain nitrogen. Other studies have shown that $P$. ostreatus is both used for nutritional and medicinal purposes [12]

Pleurotus ostreatus as health promoter and environmental restorer is gaining more importance as compared to other medicinal mushrooms. This results in an upsurge in research and development activities associated with Pleurotus ostreatus during the past two decades [13]. The chemical nature of the bioactive compounds present in this mushroom includes: polysaccharides, lipopolysaccharides, proteins, peptides, glycoproteins, nucleosides, triterpenoids, lectins, lipids, and their derivatives.

Plearotus ostreatus has antioxidant property due to the presence of compounds like ergothioneine [14]. Antioxidants are known to have protective potential in ameliorating metal induced injuries either by a metal-chelating activities or by increasing the antioxidant enzyme activities [15-18]. Therefore, this study is designed to evaluate the neuroprotective roles of Pleurotus ostreatus against neurotoxicity of mercury in albino rats.

\section{Material and methods}

\subsection{Experimental Materials}

This research was carried out at the Animal house of Department of Animal and Environmental Biology. Twenty-four albino rats weighing (50-100 g) were bought for the study from the Animal house of Faculty of Basic Medical Science. The oyster mushroom (Pleurotus ostreatus) was purchased from a commercial farm and it was air dried at room temperature. Mercury chloride was purchased from Goechem Choba. During the preparation of ethanolic extract of $P$. ostreatus, one liter of absolute ethanol was poured onto $340 \mathrm{~g}$ of dry mushroom for maceration for 72 hours in a maceration jar, and filtered through the Whatman filter paper.

The process of maceration and filtration was repeated to have a better recovery. The filtrate was placed in a rotary evaporator to separate the solvent from the ethanol. The solvent was placed in a water bath for further drying. The dry extract was diluted in distilled water to the required concentration.

\subsection{Experimental design}

A total of 24 rats weighing 50-100 g were weighed and grouped into 6 groups of four rats each. Mercury chloride was dissolved in water to produce concentrations of $100 \mu \mathrm{g} / \mathrm{kg}$ and $50 \mu \mathrm{g} / \mathrm{kg}$. One milliliter of the treatments was given from group 2 to 6. (Mercury and mushroom) Group 1 was given normal feed (control). Group 2 was treated with mushroom alone $(250 \mathrm{mg} / \mathrm{kg})$. Group 3 was treated with mercury $(50 \mu \mathrm{g} / \mathrm{kg})$ and mushroom $(250 \mathrm{mg} / \mathrm{kg})$. Group 4 was treated with mercury (100 $\mu \mathrm{g} / \mathrm{kg})$, and mushroom $(250 \mathrm{mg} / \mathrm{kg})$. Group 5 was given mercury alone $(50 \mu \mathrm{g} / \mathrm{kg})$. Group 6 was given mercury alone $(100 \mu \mathrm{g} / \mathrm{kg})$. Anti-depression, anti-stress and spatial memory tests were then carried out after 30 days of treatment using the Morris water test. 
Morris water test: this was carried out to test effects of mushroom extract in correcting mercury induced spatial memory deficit and depression. In this test, the animals were kept in a bow of water filled half way, an escape platform was kept at a particular quadrangle for the animals to easily find for escape. After a period of test the water was made opaque by adding powder milk. The animals were tested to see if they could find the escape platform through spatial memory cognition. And how they could cope with depressive condition caused by the cold water. The animals were tested five times and their responses were recorded as T1-T5.

\section{Results}

In this test, the faster the animals did swim and got to the escape platform, the more enhanced they were considered to be. Group one (control) had $53.37 \pm 5.82$ seconds and $36.51 \pm 11.75$ seconds as the longest and shortest time in the five trials (with a mean response time of $41.73 \pm 12.24 \mathrm{~s}$ ). Group two (mushroom alone $250 \mathrm{mg} / \mathrm{kg}$ ) had $35.28 \pm 10.84$ seconds and $4.11 \pm 0.73$ seconds as its longest and the shortest time (with a mean response time of $14.88 \pm 11.12 \mathrm{~s}$ ). Group three (mercury $50 \mu \mathrm{g} / \mathrm{kg}$ and mushroom $250 \mathrm{mg} / \mathrm{kg}$ ) had $34.51 \pm 15.02$ seconds and $10.28 \pm 3.35$ seconds as its longest and shortest time (with a mean response time of $22.76 \pm 17.34 \mathrm{~s}$ ). Group four (mercury $100 \mu \mathrm{g} / \mathrm{Kg}$ and mushroom $250 \mathrm{mg} / \mathrm{Kg}$ ) had $46.95 \pm 12.52$ seconds and $4.14 \pm 1.8$ seconds as its longest and shortest time (with a mean response time of $26.29 \pm 13.14 \mathrm{~s}$ ). Group five (mercury alone $50 \mu \mathrm{g} / \mathrm{kg}$ ) had $51.48 \pm 8.51$ seconds and $46.02 \pm 13.97$ seconds as its longest and shortest time (with a mean response time of 47.88 \pm 14.11 ), while group six (mercury alone $(100 \mu \mathrm{g} / \mathrm{Kg})$ had $170.75 \pm 74.64$ seconds and $14.75 \pm 10.43$ seconds as its longest and shortest time spent to swim out of the water (with a mean response time of $80.26 \pm 82.15$ ) (Fig 1 ).

A close comparison of the groups administered mushroom and mercury with their corresponding groups administered mercury alone showed that mushrooms reduced the effects of the mercury by 52.46\%, in the groups administered lower dose of mercury and mushroom while the group administered highest dose of mercury and mushroom had the mushroom reducing the effects of mercury by $67.24 \%$. When the control was used as the standard, percentage comparison, of the different groups showed that group two, three, four, five and six had $280.44 \%, 183.34 \%, 158.72 \%, 87.15 \%$ and $59.46 \%$ responses respectively. This indicated that group two with only mushroom is 2.8 times more active and faster than the control. The result showed also that the two treatments without mushroom protective effects had an expression of toxicity that made their results to be lower than the control.

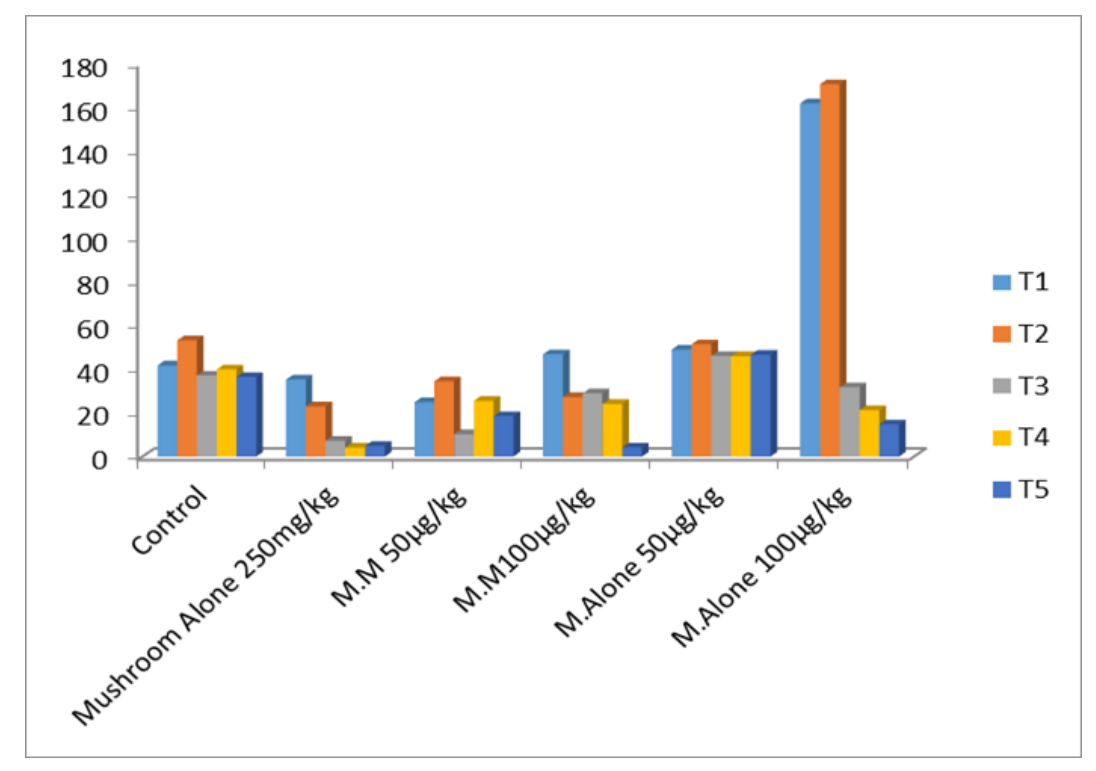

Figure 1 Effect of P. ostreatus ethanolic extract on Mercury- induced neurotoxicity using Morris water test on spatial cognitive test 
Zitte and Bernard / World Journal of Advanced Research and Reviews, 2019, 03(01), 023-028

Table 1 Morris water test results indicating effects of mushroom extracts on mercury- induced neurotoxicity expressed in spatial cognition

\begin{tabular}{|c|c|c|c|c|c|c|c|c|c|c|}
\hline Dose & & Treatment & T1 (s) & $\begin{array}{l}\text { T2 } \\
\text { (s) }\end{array}$ & T3 (s) & T4 (s) & T5 (s) & $\begin{array}{l}\text { Mean } \\
\text { (s) }\end{array}$ & $\begin{array}{l}\% \\
\text { reduction of } \\
\text { mercury } \\
\text { effects by } \\
\text { mushroom }\end{array}$ & $\begin{array}{l}\% \\
\text { performance } \\
\text { of the groups } \\
\text { compared to } \\
\text { the control }\end{array}$ \\
\hline Control & & Group 1 & $41.77 \pm 10.07$ & $53.27 \pm 5.82$ & $37.12 \pm 8.34$ & $39.98 \pm 10.04$ & $36.51 \pm 11.75$ & $41.73 \pm 12.24$ & - & \\
\hline $\begin{array}{l}\mathrm{M} . \\
\mathrm{mg} / \mathrm{kg}\end{array}$ & 250 & Group 2 & $35.28 \pm 10.84$ & $22.98 \pm 3.78$ & $7.21 \pm 1.80$ & $4.11 \pm 0.73$ & $4.84 \pm 1.05$ & $14.88 \pm 11.12$ & - & $280.44 \%$ \\
\hline $\begin{array}{l}\mathrm{Hg} . \quad \mathrm{M} \\
\mu \mathrm{g} / \mathrm{kg}\end{array}$ & 50 & Group 3 & $24.94 \pm 10.38$ & $34.51 \pm 15.02$ & $10.28 \pm 3.35$ & $25.58 \pm 13.14$ & $18.51 \pm 11.48$ & $22.76 \pm 17.34$ & $52.46 \%$ & $183.34 \%$ \\
\hline $\begin{array}{l}\text { Hg. M } \\
\mu \mathrm{g} / \mathrm{kg}\end{array}$ & 100 & Group 4 & $46.95 \pm 12.52$ & $27.3 \pm 12.59$ & $28.98 \pm 11.34$ & $24.11 \pm 12.43$ & $4.14 \pm 1.8$ & $26.29 \pm 13.14$ & $67.24 \%$ & $158.72 \%$ \\
\hline $\begin{array}{l}\mathrm{Hg} \\
\mu \mathrm{g} / \mathrm{kg}\end{array}$ & 50 & Group 5 & $49.07 \pm 10.92$ & $51.48 \pm 8.51$ & $46.14 \pm 13.85$ & $46.02 \pm 13.97$ & $46.70 \pm 13.29$ & $47.88 \pm 14.11$ & - & $87.15 \%$ \\
\hline $\begin{array}{l}\mathrm{Hg} \\
\mu \mathrm{g} / \mathrm{kg}\end{array}$ & 100 & Group 6 & $162 \pm 79.74$ & $170.75 \pm 74.64$ & $31.75 \pm 10.29$ & $21.25 \pm 7.66$ & $14.75 \pm 10.43$ & $80.26 \pm 82.15$ & - & $59.46 \%$ \\
\hline
\end{tabular}




\section{Discussion}

Morris water test was used to study spatial memory ,depression and stress, In the test, the effects of the mushroom extract was observed when group two, having only mushroom extract, expressed the smartest response against depressing cold water condition, and was able to use the evironmental cues to detect the escape platform easily by using the shortest time to find it, while the group six with the highest dose of mercury alone spent the longest time searching for the escape platform. This could be as a result of lack of mental alertness caused by high dose of mercury in group six treatment. Other effects of the mushroom was also found in the groups treated with mshroom and mercury. These groups had effective reduction in the depression as compared to the groups administered mercury alone. Group four with mushroom and high dose of mercury produces a relatively enhanced alertness as compared to group six administered only high mercury dose. These results suggested that mushroom alone served as a good anti depressant, by reducing the time taken by the rats to access the escape platform it also showed that mushroom could serve as a good antimercury agent by reducing the toxic effects of the different doses of mercury on rats behaviours.

The vulnerability of the central nervous system (CNS) to mercury toxicity has been attributed to varying factors like oxidative stress due to free radical generation, neurotransmitter disruption, and stimulation of neural excitoxins, resulting in damage to many parts of the brain [19]. Clarkson and Magos reported that the ability of mercury chloride to be converted to methylmercury which can easily cross the blood-brain-barrier and accumulate in the brain at much higher concentrations encourages neurotoxicity[14].

\section{Conclusion and Recommendation}

The importance of the extract $P$. ostreatus has been revealed in this study on how it can enhance spatial memory , learning skills,and reduces stress and depression. From this study, the results showed that mushroom has a positive effect on reducing mercury induced spatial cognitive impairment and also reduces stress and depression caused by cold water.

From this research work, it is recommended that researchers be patient and take the required time for the work to be accomplished. This is because it may need an additional time to get the best from your research work. It will also guard against taking hasty conclusions which will cause misinformation about the experimental results.

\section{Compliance with ethical standards}

\section{Acknowledgments}

We acknowledge the University of Port Harcourt, Rivers State, Nigeria for giving us the platform to carry out this research work.

\section{Disclosure of conflict of interest}

There is no conflict of interest amongst the authors of this manuscript.

\section{Statement of ethical approval}

University of Port Harcourt Ethical Committee granted approval to carry out this research work with a mild discomfort on the animal subject.

\section{References}

[1] Liu J and Lewis G. (2004). Environmental toxicity and poor cognitive outcome in chicken and adults. J environ health, 76, 130-138.

[2] Grandjean P and Landrigan PJ. (2004). Neurotbehavioural effects of developmental toxicity. The lancet neurology, 13(3), 330-8.

[3] LeBel CP, Ali SF and Bondy SC. (1992). Deferoxamine inhibits methyl mercury induces increases in reactive oxygen species formation on rat brain. Toxicol Appl Pharmacol, 112, 161-5. 
[4] Taber KH and Hurley RA. (2008). Mercury exposure: effect across the lifespan. J Neuropsychiatry Clin Neurosci 20, 4-389.

[5] Lucena GM, Franco JL, Ribas CM, Azevedo MS, Meotti FC, Gadoth VM, Dafre Al, Santors AR and farina M. (2007). Cipura paludosa extracts prevents methyl mercury- induced neurotoxicity in mice. Basic clin pharmacol toxicol, 101, 127-131.

[6] Liu WW, Jiag, Hu ZB, Zhan C, Xu QR and Zhou G. (2006). Mercury concentration on cerebrospinal fluid in patients with chronic mercury poisoning. Zhonghua, Lao Dong Wei Sheng zhi ye Bing za zhi, 24, 403-405.

[7] Farina M, Franco JL, Ribas CM, Meotti FC, Missau FC, Pizzolatti MG, Dafre AL and santos AR. (2005). Protective effect of Polygala paniculata extract against methylmercury - induced neurotoxicity in mice. J pharmpharmaacol. 57, 1503-1508.

[8] Mieiro CL, Pereria MG, Duarte AC and Pacheco M. (2011). Brain as a critical target mercury in environmentally exposed fish (Dicentrarchus labrax) - bioaccumulation and colidative stress profiles. Aguat Toxicol, 103, 233240 .

[9] Grupta R and Flora SJ. (2006). effect of centella asiatica on arsenic induced oxidative stress and mental distribution rats. J Appl Toxicol, 26, 213-222.

[10] Berlin M, Zalups RK, Fowler BA. Mercury. In: Nordberg GF, Fowler BA, Nordberg M, Friberg LT. (2007). Handbook on the Toxicology of Metals. $3^{\text {rd }}$ edition, chapter 33. New York, NY, USA: Elsevier.

[11] Cheung, PC and Lee MY. (2000). Fractionation and characterization of mushroom dietary fiber (non-starch polysaccharides) as potential nutraceuticals from sclerotia of Pleurotus tuber-regium (Fries) singer. Journal of Agriculture and Food Chemistry, 48, 3148- 3151.

[12] Wasser SP and Weis AL. (1999). Medicinal properties of substances occurring in higher Basidiomycete mushrooms: current perspective. International Journal of Medicinal Mushrooms, 1, 31-62.

[13] Patel Y, Naraian R and Singh V. (2012). Medicinal properties of Pleurotus species (Oyster mushroom): A review. World Journal of fungal and plant Biology, 3(1), 1-12.

[14] Clarkson TW and Margos. (2006). The toxicology of mercury and its chemical compounds. Critical Review Toxicology, 36.

[15] Jundal M, Garg GR, Mediratta PK and Fahim M. (2011). Protective role of melatonin on myocarchial oxidative damage induced by mercury in murine model. Hum Exp Toxicol, 30, 1489-1500.

[16] Aslani MR, Najarnozhad V and Mohri M. (2010). Individual and combined effect of meso dimercapto succinic acid and allicin on blood and tissue lead content in mice. Planta medica, 76(3), 241-244.

[17] Rao MV, Purohnit A and patel T. (2010). Melatonin protection on mercury exerted brain toxicity in the rat. Drug Chem Toxicol, 33, 209-216.

[18] Simoes-Pires EN, Prozza RL, Hope JB, Menezes Bele M and Salbergo CG. (2014). Berberine was neuroprotective against an in vitro model of brain ischemia: survival and apoptosis pathways involved. Brain Res, 1557, 26-33.

[19] Bernhoft RA. (2012). Mercury toxicity and treatment: a review of the literature. Journal of Environmental and Public Health, Article ID 460508, 10 pages.

\section{How to cite this article}

Zitte L.F and Bernard S.F. (2019). Morris water maze test on neuroprotective effects of ethanolic extract of oyster mushroom (Pleurotus ostreatus) against neurotoxicity of mercury chloride in albino rats (Rattus norvegicus). World Journal of Advanced Research and Reviews, 3(1), 23-28. 